\title{
Pulsing with Triton X-100 Improves Hydration and Vase Life of Cut Sunflowers (Helianthus annuus L.)
}

\author{
Rodney B. Jones', Margrethe Serek ${ }^{2}$, and Michael S. Reid \\ Department of Environmental Horticulture, University of California, Davis, \\ CA 95616
}

\begin{abstract}
The vase life of cut sunflowers given a simulated transport period ( 3 days dry storage at $8 \mathrm{C}$ ) was significantly enhanced by a l-hour pulse with $0.01 \%$ Triton $\mathrm{X}-100$ administered before storage. The Triton pulse increased solution uptake during the l-hour pulse, decreased fresh weight loss during dry storage, and significantly improved water uptake thereafter, resulting in greater leaf turgidity and longer vase life. Leaf stomata] conductance measurements indicated that Triton X-100 maintained stomatal opening at a higher level during the pulse and after storage, but had no effect during dry storage. Chemical name used: octylphenoxypolyethoxyethanol (Triton X-100).
\end{abstract}

Cut sunflowers, a recent addition to the florist trade, have proved to be a popular and salable crop (Bill Suyeyasu, wholesale florist, personal communication). Vase life in cut sunflowers is often determined by leaf, rather than flower, senescence, as leaves tend to wilt and discolor 3 to 5 days after harvest. Furthermore, leaf desiccation seems to be accelerated by dry storage and transport; flowers transported dry for more than $24 \mathrm{~h}$ often have irreversibly wilted leaves. Apart from recommendations that sunflowers be stored at 2 to 5C, and treated with Carnation-Chrysal (Nowak and Rudnicki, 1990; Vaughan, 1988), little is known of the postharvest handling requirements for sunflowers.

Pulsing cut chrysanthemums [Dendranthema $\times$ grandiflorum (Ramat.) Kitamura] with the nonionic detergent Tween 20 (0.017. to $0.1 \%$ ) for $24 \mathrm{~h}$ significantly improved vase life (Durkin, 1981), while roses (Rosa hybrids L.) treated with Agral LN (0.01\%) before dry storage had a significantly longer post-storage vase life (Perik and van Doom, 1988). The beneficial effect of Agral also was demonstrated in fresh (nonstored) cut roses (Ruting, 199 1), while another detergent, Physan-20, significantly improved water uptake in chry-

Receivedforpublication11 Jan. 1993. Accepted for publication 21 June 1993. Flowers were kindly supplied by Bill Suyeyasu, Wholesale Florist Inc. Funding for this study was provided by the AustralianDept.of Industry, Technology, and Commerce BilateralScienceExchange Program; Danish Agricultural and Veterinary Council (grant 13-4549); Foundation of Hofmansgave; Foundation of Ib Henriksen;andtheCarlsbergFoundation.We gratefully acknowledge the skilled technical assistance of Mercedes Fernando Sanchez. The cost of publishing this paper was defrayed in part by the paymentofpagecharges. Under postal regulations, this paper therefore must be hereby marked advertisernent solely to indicate this fact.

'Current address: Institute of Plant Sciences, Knoxfield, P.O. Box 174 Ferntree Gully, Victoria 3156, Australia.

${ }^{2}$ Current address: The Royal Veterinary and AgriculturalUniv.,SectionforHorticulture,Rolighedsvej 23. DK-1958 Frederiksberg C.. Denmark. santhemum (D'Hont and van der Sprong, 1988) and Gypsophila (W.G. van Doom, personal communication). Jones et al. (1993) reported that $0.01 \%$ Agral 600 improved stem hydraulic conductivity, fresh weight, and vase life of Thryptomene calycina (Lindl.) Stapf, possibly by bypassing bacterial-induced blockages of the xylem vessels and by dissolving air embolisms.

This paper details the effect of a Triton $\mathrm{X}-100$, nonionic detergent, pulse on the post-storage hydration and vase life of cut sunflowers.

Cut sunflowers were obtained from a local wholesaler and transported to the laboratory within $48 \mathrm{~h}$ of harvest. Stems were trimmed (in air) to $60 \mathrm{~cm}$ and placed in deionized water (DI), or $0.01 \%, 0.02 \%$, or $0.10 \%$ Triton X-100 for 30,60 , or $180 \mathrm{~min}$ at $20 \mathrm{C}(\mathrm{n}=10)$ to investigate optimal pulse concentrations and time. All flowers were weighed before and after the pulse to determine solution uptake and flower fresh weight (FW). After being pulsed, sunflowers were packed in a standard cardboard, cut-flower box and stored dry for 3 days at 8C. Flowers were weighed immediately after storage $(2 \mathrm{~cm}$ was cut from the base of each stem) and placed in DI water in a controlled environment $(21 \mathrm{C}, 12 \mathrm{~h}$ of 15 $\mu \mathrm{mol} \cdot \mathrm{s}^{-1} \cdot \mathrm{m}^{-2} \mathrm{cool}-\mathrm{white}$ fluorescent light each day, $60 \%$ relative humidity) for vase life evaluation. Vase life was evaluated three times per day and considered terminated when leaves wilted or began to blacken.

The most effective Triton X-100 pulse $(0.01 \%$ for $1 \mathrm{~h})$ was applied to sunflowers that had been stored for 3 days at $8 \mathrm{C}$. Flowers were placed in DI water under controlled conditions immediately after storage, and post-storage solution uptake and flower FW were recorded daily. In a separate experiment, continuously treating fresh (nonstored) sunflowers with $0.001 \%$ Triton X-100 was tested. Ten flowers were placed in individual test tubes that contained either DI water or Tnton X-100 under controlled conditions, and FW was recorded daily.

Stomatal conductivity was measured be- fore and after a 60 -min pulse with DI water or 0.019 . Triton X-100 using a LI-COR (Lincoln, Neb.) Li-1600 steady-state porometer. Measurements were taken from the tip of one basal leaf per flower $(n=10)$. Stomatal conductance also was recorded immediately after 3 days of dry storage at $8 \mathrm{C}$, and daily after flowers were placed in DI water under controlled conditions.

All sunflowers were stored dry at $8 \mathrm{C}$ for 3 days to simulate postharvest handling and transport. Although post-storage vase life of flowers stored at 0 to $\mathrm{IC}$ was similar to those stored at $8 \mathrm{C}$ (data not shown), we decided to store sunflowers at $8 \mathrm{C}$ to reproduce commercial conditions.
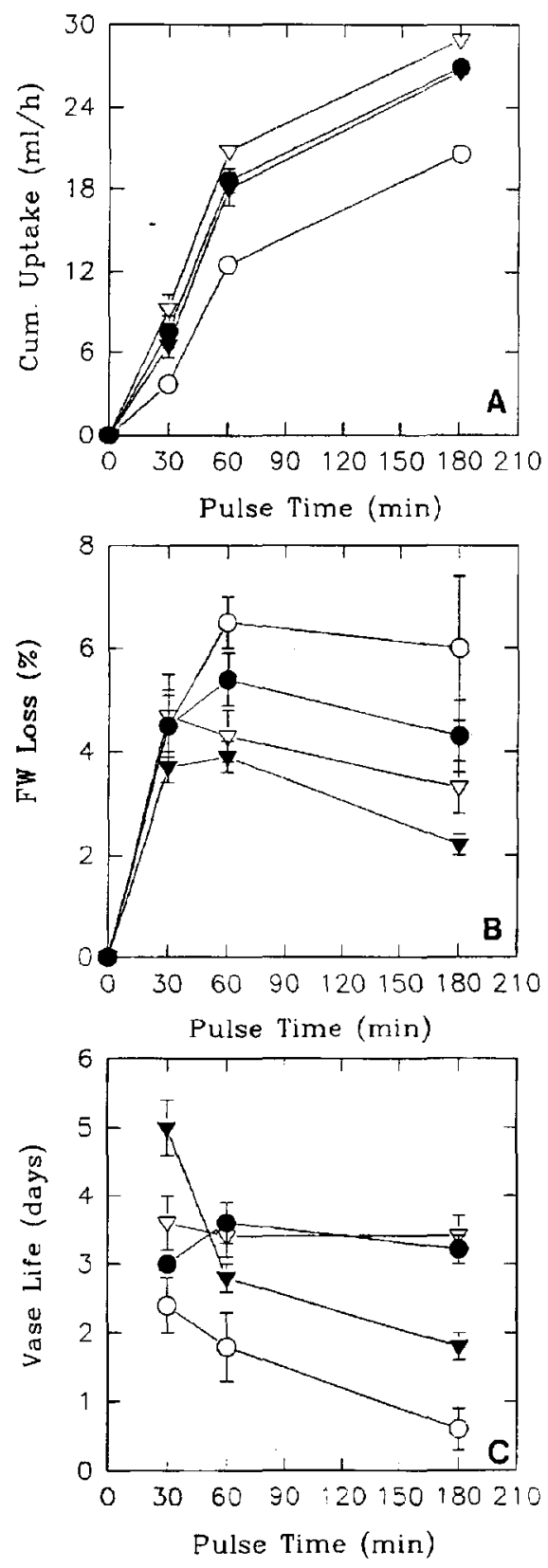

Fig. 1. (A) Cumulative solution uptake during the prestorage pulse, (B) FW loss during dry storage, and (C) post-storage vase life in cut sunflower stems pulsed in DI water $(O)$, or $0.01 \%$ $(\circlearrowleft), 0.02 \%(\nabla)$, or $0.1 \%$ Triton $\mathrm{X}-100(\nabla)$ for 30,60 , or $180 \mathrm{~min}$. Bars represent SE. 


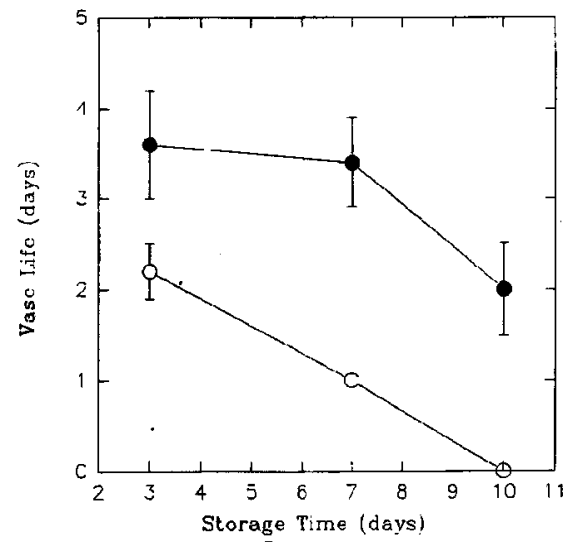

Fig. 2. Changes in the vase life of cut sunflowers after dry storage at $8 \mathrm{C}$ for 3,7 , or 10 days. Stems were pulsed before storage with DI water $(\mathrm{O})$ or $0.01 \%$ Triton X-100 (O). Bars represent SE.

Triton X-100 significantly increased solution uptake by sunflowers (Fig. 1A). All Triton concentrations improved solution uptake compared to DI water, particularly during a 30- or 60-min pulse. Flowers pulsed with all concentrations of Triton also maintained a significantly higher FW after 30-, 60-, and 180-min pulses (data not shown). Flowers pulsed with Triton for 260 min lost significantly less FW during the 3 days of dry storage at 8C (Fig. 1B). Weight loss was inversely proportional to Triton concentration, i.e., the higher the pulse concentration, the lower the FW loss during storage.

Post-storage vase lives further reflected the improved hydration of flowers pulsed with Triton (Fig. 1C). Vase life was significantly shorter in flowers pulsed with DI water before dry storage, and declined with longer pulse time. In contrast, vase life increased slightly as the pulse time was extended in flowers treated with $0.01 \%$ Triton, remained static in those pulsed with $0.02 \%$ Triton, or declined as pulse time was extended in stems treated with $0.1 \%$ Triton. These data indicate that $0.01 \%$ or $0.02 \%$ Triton pulses that lasted $260 \mathrm{~min}$ were optimal for improving post-storage vase life. pulses with $0.1 \%$ Triton that exceeded 30 tin, however, reduced vase life, possibly due to toxic effects, as leaves on those stems pulsed for $\geq 60$ min displayed an increased incidence of leaf blackening (data not shown). Furthermore, placing fresh (nonstored) sunflowers continuously in a 0.00170 Triton solution also significantly increased the incidence of leaf blackening (data not shown). These results indicate that Triton can be toxic to sunflower leaves if concentrations are too high, and confirms the interpretation of leaf damage in stems pulsed with high concentrations of Triton $(0.1 \%)$ for extended periods ( $>60 \mathrm{~min}$ ).

As a result, all subsequent experiments used a 60 -min prestorage pulse of $0.01 \%$ Triton. Stems pulsed with DI water or $0.01 \%$ Triton for $60 \mathrm{~min}$ were stored dry for 3,7 , or 10

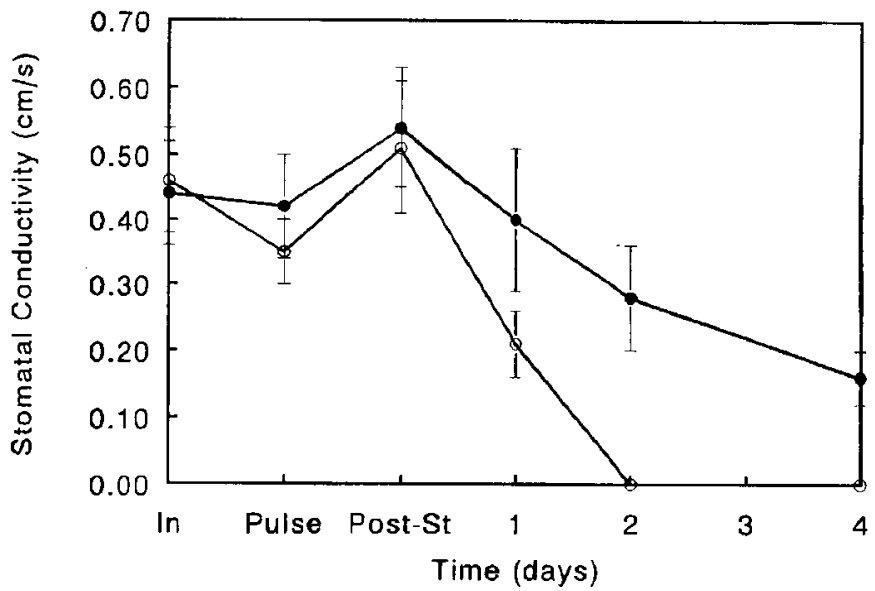

Fig. 3. Stomatal conductivity (in centimeters per second) measured in sunflower leaves before (In) and after a 1-h pulse (Pulse) in DI water (O) or $0.01 \%$ Triton X-100 (O). Flowers were stored for 3 days at $8 \mathrm{C}$, and conductance was measured immediately after storage (Post-St) and daily during vase life evaluation at $20 \mathrm{C}$. Bars represent $\mathrm{SE}$.

days at $8 \mathrm{C}$ to determine the maximum storage period for cut sunflowers. Flowers pulsed with DI water showed a linear decline in post-storage vase life (Fig. 2). Vase life was significantly extended in stems pulsed with Triton for all storage periods. Thus, sunflowers pulsed with Triton may be stored for up to 7 days at $8 \mathrm{C}$ without a significant reduction in vase life.

The extension in vase life by Triton X-100 can be attributed to three pulse effects. First, Triton improved cut sunflower hydration before storage by increasing solution uptake and FW of the flowers during the pulse (Fig. 1A). Furthermore, FW loss during the dry storage period was significantly reduced in stems pulsed with Triton (Fig. 1B), resulting in sunflowers with a more turgid appearance immediately after dry storage. Last, post-storage dehydration with DI water was significantly higher $(>30 \%)$ in sunflowers pulsed with Triton (data not shown).

These results agree with previous studies that indicate nonionic detergents (e.g., Tween 20 or Agral) improved hydration in cut chrysanthemums and roses (Durkin, 1981; Perik and van Doom, 1988; Ruting, 1991), and cut branches of Thryptomene calycina (Jones et al., 1993). One major difference between this study and previous work is in pulse length. Continuous application (Ruting, 1991) or 24h pulses (Durkin, 198 1; Perik and van Doom, 1988; Jones et al., 1993) gave beneficial results with chrysanthemums, roses, and $T$. calycina, whereas we found a 1-h pulse was optimal for Triton X-100. Pulsing with these detergents, therefore, significantly improved flower hydration by increasing the solution flow through excised stems of $T$. calycina (Jones et al., 1993), as measured by hydraulic conductance or solution uptake in cut sunflowers (Fig. 1A). The detergent possibly increased flow by dissolving air bubbles formed in stems during harvest and transport.
Stomatal conductivity declined significantly $(11 \%)$ during a 60 -min pulse with DI water (Fig. 3), but this decline was not evident in leaves treated with $0.01 \%$ Triton. Conductivity increased in both treated and control stems during 3 days of dry storage at $8 \mathrm{C}$, but declined more rapidly in control leaves after storage than in those pulsed with Triton $(40 \%$ vs. 5\% decline during Day 1, respectively). These data indicate that Triton maintained stomatal opening and, therefore, did not control the transpiration rate by inducing stomatal closure. Stomatal closure is generally associated with senescence, as was seen in tomato (Lycopersicon esculentum Mill.) plantsplaced at $2 \mathrm{C}$ for $48 \mathrm{~h}$ (King, 1987).

\section{Literature Cited}

Durkin,D.J.1981. Factors effecting [sic] hydration of cut flowers. Acts Hort. 113: 109-1 15.

D'Hont, K. and J.N.M. van der Sprong. 1988. Postharvesttreatment of chrysanthemum. Acts Hort.261:305-307.

Ho, I., F.E. Below, and R.H. Hageman. 1987. Effect of head removal on leaf senescence of sunflower. Plant Physiol. 83:844-848.

Jones, R.B., J.D. Faragher, and W.G. van Doom. 1993. Waterrelations of cut flowering branches of Thryptomene calycina (Lindl.) Stapf. (Myrtaceae).Postharv. Biol. Technol. 3:57-67.

King, A.I. and M.S. Reid. 1987. Diurnal chilling sensitivity and desiccation in seedlings of tomato. J. Amer. Soc. Hort. Sci. 112:821-824.

Nowak, J. and R.M. Rudnicki. 1990. Postharvest handlingandstorageofcutflowers,floristgreens and potted plants. Timber Press, Portland, Ore.

Perik, R.R.J. and W.G. van Doom. 1988. Voorbehandeling met Agral LN gaat vaat verstopping bij roos tegen. Vakblad voor de Bloemisterij 5:58-59.

Ruting, A. 1991. Effects of wetting agents and cut flower food on the vase life of cut roses. Acts Hort. 298:69-73.

Vaughan, M. 1988. The complete book of cut flower care. Timber Press, Portland, Ore. 